\title{
Local biodiversity change reflects interactions among changing abundance, evenness and richness
}

Shane A. Blowes, German Centre for Integrative Biodiversity Research (iDiv) Halle-JenaLeipzig, Germany; Department of Computer Science, Martin Luther University HalleWittenberg, Halle (Salle), Germany. shane.blowes@idiv.de

Gergana N. Daskalova, School of GeoSciences, University of Edinburgh, Scotland EH9 3FF. gndaskalova@gmail.com

Maria Dornelas, Centre for Biological Diversity, University of St Andrews, KY16 9TH. maadd@st-andrews.ac.uk

Thore Engel, German Centre for Integrative Biodiversity Research (iDiv) Halle-Jena-Leipzig, Germany; Department of Computer Science, Martin Luther University Halle-Wittenberg, Halle (Salle), Germany. thore.engel@idiv.de

Nicholas J. Gotelli, Department of Biology, University of Vermont, Burlington, VT 05405 USA. Nicholas.Gotelli@uvm.edu

Anne Magurran, Centre for Biological Diversity, University of St Andrews, KY16 9TH. aem1@st-andrews.ac.uk

Inês S. Martins, Leverhulme Centre for Anthropocene Biodiversity and Department of Biology, University of York, York YO10 5DD, UK. ines.martins@york.ac.uk

Brian McGill, School of Biology and Ecology and Mitchell Center for Sustainability Solutions,

Daniel J. McGlinn, Department of Biology, College of Charleston, Charleston, SC.

danmcglinn@gmail.com

Alban Sagouis, German Centre for Integrative Biodiversity Research (iDiv) Halle-Jena-Leipzig, Germany; Department of Computer Science, Martin Luther University Halle-Wittenberg, Halle (Salle), Germany. alban.sagouis@idiv.de

Hideyasu Shimadzu, Department of Mathematical Sciences, Loughborough University, LE11 3TU, UK; Graduate School of Public Health, Teikyo University, Tokyo, Japan.

H.Shimadzu@lboro.ac.uk

Sarah R. Supp, Data Analytics Program, Denison University, Granville, OH 43023 USA. supps@denison.edu

Jonathan M. Chase, German Centre for Integrative Biodiversity Research (iDiv) Halle-JenaLeipzig, Germany; Department of Computer Science, Martin Luther University HalleWittenberg, Halle (Salle), Germany. jonathan.chase@idiv.de 
49 Running title: Characterising multicomponent diversity change

Keywords: biodiversity change, abundance, evenness, species richness, rarefaction

54 Corresponding author: Shane Blowes, German Centre for Integrative Biodiversity Research

55 (iDiv) Halle-Jena-Leipzig, Deutscher Platz 5e, Leipzig 04103, Germany. shane.blowes@idiv.de $56+493419733254$. 


\section{Abstract}

59 Biodiversity metrics often integrate data on the presence and abundance of multiple species. Yet

60 our understanding of how changes to the numbers of individuals, the evenness of species'

61 relative abundances, and the total number of species covary remains limited, both theoretically

62 and empirically. Using individual-based rarefaction curves, we first show how expected positive

63 relationships among changes in abundance, evenness and richness arise, and how they can break

64 down. We then examined the interdependency between changes in abundance, evenness and

65 richness more than 1100 assemblages sampled either through time or across space. As expected,

66 richness changes were greatest when abundance and evenness changed in the same direction,

67 whereas countervailing changes in abundance and evenness acted to constrain the magnitude of

68 changes in species richness. Site-to-site variation in diversity was greater than rates of change

69 through time. Moreover, changes in abundance, evenness, and richness were often spatially

70 decoupled, and pairwise relationships between changes in these components were weak between

71 sites. In contrast, changes in species richness and relative abundance were strongly correlated for

72 assemblages sampled through time, meaning temporal changes in local biodiversity showed

73 greater inertia and stronger relationships between the components changes when compared to

74 site-to-site variation. Both temporal and spatial variation in local assemblage diversity were

75 rarely attributable solely to changes in assemblage size sampling more or less of a static species

76 abundance distribution. Instead, changing species' relative abundances often dominate local

77 variation in diversity. Moreover, how these altered patterns of relative abundance combine with

78 changes to total abundance strongly determine the magnitude of richness changes.

79 Interdependencies found here suggest looking beyond changes in abundance, evenness and 
bioRxiv preprint doi: https://doi.org/10.1101/2021.08.29.458087; this version posted August 30, 2021. The copyright holder for this preprint (which was not certified by peer review) is the author/funder, who has granted bioRxiv a license to display the preprint in perpetuity. It is made available under aCC-BY-NC 4.0 International license.

80 richness as separate responses offering unique insights into diversity change can increase our

81 understanding of biodiversity change.

82

83 


\section{Introduction}

85 Measures of biodiversity and its change are frequently used to determine the magnitude,

86 direction and pace of ecosystem modifications (Diaz et al. 2019). Descriptions of the distribution

87 and abundance of organisms are central to basic ecological research (Krebs 1972, Andrewartha

$88 \&$ Birch 1984), and biodiversity itself is a multifaceted concept that combines information on the

89 distribution and abundance of multiple species. There have been numerous metrics proposed to

90 quantify different aspects of biodiversity (e.g., Hill 1973, Gotelli and Colwell 2001, Magurran \&

91 McGill 2011, Chao and Jost 2012), most of which depend on sample effort and scale

92 (Rosenzweig 1995, Whittaker et al. 2001, McGill 2011a, Chase \& Knight 2013). This inherent

93 complexity in the quantification of biodiversity poses significant challenges for syntheses of its

94 temporal and spatial variation.

96 Here, we argue that in order to understand biodiversity change, it is critical to look beyond

97 aggregate metrics of biodiversity. Specifically, we need to examine how changes in the key

98 components that lead to these aggregate metrics interact and combine with each other. Currently,

99 different components that underlie biodiversity represent important, but largely independent lines

100 of evidence for biodiversity change. For example, one body of work on biodiversity change is

101 focused on quantifying total abundances of all species within assemblages, such as recent work

102 documenting declines of birds (e.g., Rosenberg et al. 2019) and insects (Wagner 2020). A related

103 body of work focuses instead on population-level 'winners' and 'losers' within assemblages

104 (McKinney \& Lockwood 2000), species with increasing and decreasing trends in occupancy or

105 abundance (e.g., WWF 2020). However, changes in the means of these metrics do not capture

106 the variability and nuance in either the assemblage- and population-level abundance trends 
107 across space and among taxa (e.g., van Klink et al. 2020, Daskalova et al. 2020a, Leung et al.

108 2020). Moreover, trends in total assemblage abundance provide only one window into potentially

109 complex changes that could be occurring in other components of biodiversity, and while changes

110 to species' relative abundances do influence biodiversity metrics, population-level trends

111 themselves cannot be used to calculate assemblage-level (i.e., biodiversity) metrics (e.g.,

112 Dornelas et al. 2019). Even when quantifying similar response metrics (i.e., species richness),

113 syntheses of biodiversity change in space due to differential land use conditions have found

114 declines of species richness (e.g., Newbold et al. 2015, 2018), whereas analyses of time series

115 have shown that, on average, species richness increases roughly offset decreases (Dornelas et al.

116 2014, Blowes et al. 2019), despite often significant modifications to climate and habitat (Antão

117 et al. 2020a, Daskalova et al. 2020b). Finally, the prediction that human activities likely impact

118 species relative abundances more frequently than they do species occurrences (Chapin et al.

119 2000), has not resulted in a strong focus on assemblage-level evenness in existing syntheses (but

120 see, e.g., Crowder et al. 2010, Zhang et al. 2012, Jones \& Magurran 2018). Importantly, changes

121 in all these components, abundance, evenness and richness, contribute to variation in

122 biodiversity. Yet little is known about how components are changing in combination within

123 assemblages, and whether certain combinations act to constrain observed biodiversity change.

125 The biodiversity estimated from a given (local) sample depends largely on two factors (see e.g., 126 He and Legendre 2002, McGill 2011a). First, the total number of individuals (Fisher et al. 1943,

127 Preston 1962), whereby fewer individuals are expected to (non-linearly) lead to fewer species in

128 a given sample. Second, the total number of species and their relative abundances within the

129 species pool, which we refer to as the Species Abundance Distribution (SAD; McGill et al. 
130 2007). Samples will have lower species richness when the species pool has relatively few highly

131 abundant species and many rare species (i.e., less even SADs), compared to samples from a

132 species pool of the equivalent size with more equitable species abundances. Whenever two or

133 more samples across space or time differ in the total number of individuals, the shape of the

$134 \mathrm{SAD}$, or both, there will be changes in most metrics of biodiversity. However, changes in

135 abundance and the SAD are not always correlated, and, when decoupled, the magnitude and

136 direction of change in derived biodiversity metrics could differ considerably.

138 Variation in the total number of individuals is a long-standing, first-order explanation of

139 variation in richness (Fisher et al. 1943, Coleman et al. 1982, Srivastava \& Lawton 1998, Gaston

140 2000, Scheiner \& Willig 2005, Storch et al. 2018). A positive relationship between numbers of

141 individuals and species richness can be derived via multiple mechanisms (Scheiner \& Willig

142 2005), and is sometimes termed the 'more-individuals hypothesis' (Srivastava \& Lawton 1998),

143 or, in the context of species-area relationships, the 'passive sampling hypothesis' (Coleman et al.

144 1982). Species richness has been posited to increase in places that are larger (Connor \& McCoy

145 1979) or more productive (Wright 1983), simply because of increased numbers of individuals.

146 Likewise, some anthropogenic drivers can influence the number of individuals in assemblages

147 (e.g., via eutrophication, exploitation, harvesting or land clearing), potentially impacting

148 biodiversity due to changes to the total number of individuals (Newbold et al. 2015, Blowes et al.

1492020 , Jones et al. 2020). If biodiversity varies primarily via changes in the numbers of

150 individuals, positive relationships between altered numbers of individuals and species richness

151 changes are expected. In such cases, however, other metrics of species diversity that control for 
152 variation in numbers of individuals, such as the richness expected for a given number of

153 individuals — known as rarefied richness — should be relatively unchanged.

155 Changes to the shape of the SAD can also drive biodiversity change through time or space. For

156 example, co-occurrence and coexistence of species can be altered by changes to resource

157 diversity (MacArthur 1965), environmental or habitat heterogeneity (Tilman 1982, Shmida \&

158 Wilson 1985), interspecific interactions (e.g., keystone predation; Paine 1974, Menge et al.

159 2020), biological invasions (Vilà et al. 2011), and external perturbations (Hughes et al. 2007).

160 Alterations to any of these features can change biodiversity by changing species' relative

161 abundances and the size of the species pool (via species additions or subtractions).

162 Anthropogenic factors can also favour some species and disfavour others, potentially altering the

163 relative abundance of species (e.g., due to selective exploitation; Blowes et al. 2020), or the size

164 of the species pool (e.g., species with large ranges replacing those with small ranges, Newbold et

165 al. 2018). In such cases, biodiversity change will be characterised by positive relationships

166 between species richness change and changes in metrics sensitive to relative abundance, such as

167 rarefied richness, evenness and diversity metrics sensitive to species' relative abundances.

169 The changing components of biodiversity can covary in different and informative ways. Yet, to

170 date, there has been little exploration of this covariation in time or space, nor of the theoretical

171 linkages. For example, whether total abundances and the evenness of species' relative

172 abundances change in similar or decoupled ways, and how this influences biodiversity change is

173 largely unknown. However, syntheses of relationships between different biodiversity metrics,

174 which can reflect different combinations of component changes, have typically found 
175 relationships to be weak. For example, Stirling and Wilsey (2001) showed that although strong

176 positive correlations between species richness, diversity and evenness metrics were expected

177 from a neutral model (Caswell 1976), there was considerable variation in the strength, and even

178 the sign of the relationships in 323 empirical comparisons. Similarly, Soininen et al. (2012)

179 examined temporal $(n=212)$ and spatial variation $(n=17)$ in aquatic datasets, and again found

180 considerable heterogeneity in the relationship between richness and evenness. Using data from

18191 assemblages, McGill (2011b) concluded that most biodiversity metrics align with three axes

182 of empirical variation (total abundance, evenness and richness); components subsequently shown

183 to be relatively uncorrelated across space for a subset of 37 of the 91 assemblages (Chase et al.

184 2018). Collectively, these studies suggest that static biodiversity estimates are multidimensional,

185 and that different metrics can covary or be unrelated.

187 Where ecologists have quantified changes in multiple components of local diversity, the focus

188 has typically been on averages across assemblages, where each component is treated as a

189 separate, independent response. For example, analyses of the local assemblages documented by

190 the BioTIME database (Dornelas et al. 2018) show that numbers of individuals, species richness,

191 and dominance (the complement of evenness) are highly variable among datasets, but on

192 average, have no directional trend (Dornelas et al. 2014, Jones \& Magurran 2018, Blowes et al.

193 2019). On the other hand, analyses of the PREDICTS database (Hudson et al. 2017)

194 documenting spatial contrasts between assemblages in more pristine habitats with those in

195 different land use categories, show that human-altered habitats frequently have fewer species and

196 often fewer individuals (Newbold et al. 2015, 2020). However, these results describe average 
197 changes across assemblages estimated independently, whereas, as we describe in more detail

198 below, component changes are unlikely to be completely independent.

200 Here, we first overview the theoretical context for how the main components underlying local

201 biodiversity (total abundance, evenness and species richness) can change in time or space using

202 individual-based rarefaction curves. We focus on six simplified scenarios of change with

203 contrasting patterns of covariation among component changes, showing that the signs of changes

204 in total abundance and evenness strongly determine whether all components can be expected to

205 have positive pairwise relationships. We then empirically assess the relationships between

206 abundance, evenness and richness changes using compilations of ecological assemblage data.

207 This includes data from 351 assemblages varying through time and 774 assemblages monitored

208 across space. In the face of natural and anthropogenically-driven environmental variation in time

209 and space, we ask whether changes in the components of local biodiversity show positive

210 relationships (i.e., change in the same direction). Or, are component changes sufficiently

211 heterogeneous that variation in biodiversity depends on which of the underlying components

212 (numbers of individuals or the SAD) are changing, and how the different component changes

213 combine?

215 Quantifying the multicomponent nature of biodiversity change

217 Individual-based rarefaction curves (Hurlbert 1971, Gotelli \& Colwell 2001) are well suited for

218 visualising and characterising empirical variation in total abundance, evenness and species

219 richness (Appendix 1; Figure 1; Cayuela et al. 2015, Chase et al. 2018, McGlinn et al. 2019). 
220 We use four metrics associated with the IBR (Figure 1) to show how changes in the different

221 components are related to each other. Plotting pairwise relationships between changes in species

222 richness $(\Delta S)$ and total abundance ( $\Delta N$; Fig. 2a), and two metrics sensitive to changes in relative

223 abundance $\left(\Delta S_{\mathrm{n}}\right.$, Fig. 2 b; and, $\Delta S_{\text {PIE }}$, Fig. 2c; see Chase et al. 2018, and Appendix 1 for further

224 details on metrics and interpretation) show whether changing components have positive

225 relationships (i.e., the same sign) or otherwise, and how altered patterns of total and relative

226 abundance combine in terms of changes in species richness. We next outline how expectations of

227 positive relationships between changing components arise and break down using six simplified

228 scenarios of change.

230 Altered numbers of individuals, but no change to the SAD, can underpin differences in diversity

231 between assemblages. Changes only to the number of individuals being passively sampled from

232 the same underlying $\mathrm{SAD}$ (Figure 2d) result in $\Delta S$ and $\Delta N$ being positively related with the same

233 sign (Figure 2a), whereas $\Delta S_{\mathrm{n}}$ and $\Delta S_{\text {PIE }}$ will be approximately zero (and have a weak or no

234 relationship with $\Delta S$, Figure $2 \mathrm{~b}$, c, respectively). This has been variously referred to in the

235 literature as a sampling effect, the rarefaction effect, the more-individuals hypothesis, and the

236 passive sampling hypothesis (Coleman et al. 1982, Gotelli \& Cowell 2001, Palmer et al. 2000,

237 Srivastava \& Lawton 1998).

239 The expected positive relationship between changes in richness $(\Delta S)$ and abundance $(\Delta N)$

240 weakens when altered numbers of species are associated only with changes to relative abundance

241 (i.e., $\Delta N \sim 0$ ). Changes in species richness associated with relatively rare species would be seen

242 in a positive relationship between $\Delta S$ and $\Delta S_{\mathrm{n}}$ (Figure 2e), whereas SAD changes due, for e.g., to 
243 increased numbers of common species, increased evenness, or increases to the size of the species

244 pool result in a positive relationship between $\Delta S$ and $\Delta S_{\text {PIE }}$ (Figure 2f). Even where numbers of

245 individuals increase $(\Delta N>0)$, expected gains in species richness can be constrained by decreased

246 evenness, resulting in no changes to species richness (Figure 2g), or possibly, a negative

247 relationship between $\Delta S$ and $\Delta N$, when changes to the SAD are sufficiently strong (Figure 2h).

248 Alternately, opposing changes to total numbers of individuals and evenness could result in a

249 positive relationship between $\Delta S$ and $\Delta N$ if, for example, the effects of more individuals on

250 species richness outweighs that of decreased evenness (Figure 2i).

252 A positive relationship between $\Delta S$ and $\Delta S_{\mathrm{n}}$ (Figure 2b) can occur due to altered numbers of rare

253 species (Figure 2e), or changes to the species pool size or the evenness of relative abundances

254 (Figure 2f). However, changes in species richness associated only with altered numbers of

255 individuals (Figure 2d), or changes in total abundance and evenness with opposing signs (Figure

$2562 \mathrm{~g}-\mathrm{i})$ can weaken or reverse the expectation of a positive relationship between $\Delta S$ and $\Delta S_{\mathrm{n}}$.

258 As assemblages become more or less even, numbers of species are expected to change in a

259 similar direction (He \& Legendre 2002), resulting in an expected positive relationship between

$260 \Delta S$ and $\Delta S_{\text {PIE }}$ (Figure 2c). However, again, the expectation of positive relationship between

261 changes in richness $(\Delta S)$ and evenness $\left(\Delta S_{\text {PIE }}\right)$ can be weakened if richness changes are

262 associated only with altered numbers of individuals (Figure 2d), or where only the number of

263 rare species are changing (Figure 2e). Finally, changes in total abundance $(\Delta N)$ and evenness

$264\left(\Delta S_{\text {PIE }}\right)$ with opposing signs (Figure $\left.2 \mathrm{~g}-\mathrm{i}\right)$ will tend to weaken and possibly reverse the expected

265 positive relationship between $\Delta S$ and $\Delta S_{\text {PIE }}$. Such changes could occur, for example, if altered 
environmental conditions strongly favour some species and disfavour others, resulting in higher

267 abundances of one or only a few dominant species.

269 Our rarefaction-based framework shows that the key to understanding any breakdown of the 270 expected positive relationships between changing abundance, evenness and richness are in the

271 signs of changes in total abundance and evenness (i.e., $\Delta N$ and $\Delta S_{\text {PIE). }} . \Delta N$ is associated with the 272 curve stretching or contracting along the x-axis, and $\Delta S_{\text {PIE }}$ characterises changes that flex the

273 curve up or down from the base along the y-axis (Olszewski 2004). If $\Delta N$ and $\Delta S_{\text {PIE }}$ have

274 different signs, the strength of their relationships with $\Delta S$ will be diminished, and the likelihood

275 of patterns of assemblage change moving from the lower left and upper right quadrants

276 (component changes with the same sign and positive relationships) towards, and possibly into,

277 the upper left and lower right quadrants (opposing signs and negative pairwise relationships) of

278 Figure 2a-c increases.

280 Overall, we expect to see positive relationships between abundance, evenness and richness

281 changes. However, more complex interdependencies are possible, and the assumption that these

282 components represent independent response variables (e.g., Dornelas et al. 2014, Newbold et al.

283 2015) is questionable. To evaluate empirical relationships among component changes we use

284 data from 587 studies and 1125 assemblages and models that allow for correlations between

285 component changes; 299 of these studies examined changes through time, and 288 document

286 comparisons across spatial locations. We expect to find larger changes in species richness for

287 assemblages where total abundance and evenness move in the same direction (i.e., $\Delta N$ and $\Delta S_{\text {PIE }}$

288 have the same sign, and all pairwise relationships between changes in abundance, evenness and 
richness are positive). If observed local diversity changes are dominated by altered total

290 abundances and species richness, the strong positive relationships between $\Delta S$ and $\Delta N$, but

291 weaker relationships between $\Delta S$ and $\Delta S_{\mathrm{n}}$, as well as between $\Delta S$ and $\Delta S_{\text {PIE }}$ should emerge.

292 Alternatively, strong relationships between either $\Delta S$ and $\Delta S_{\mathrm{n}}$ and/or $\Delta S$ and $\Delta S_{\mathrm{PIE}}$, accompanied

293 by a weaker relationship between $\Delta S$ and $\Delta N$, would indicate that changes to the SAD are the

294 dominant component of local assemblage change.

\section{Methods}

297 Overview

298 We took a comparative approach to examine relationships between changes in total abundance,

299 evenness and species richness. Specifically, we sought data documenting assemblages varying

300 either through time or space, in one of either predominantly naturally-varying or perturbed

301 environments. The saturating, asymptotic nature of the IBR means that many common functions

302 used in ecology, such as the Michaelis-Menten or the type-II functional response offer multiple

303 parameterisations for inferences regarding different parts of the curve (see Bolker 2008 for

304 examples of different parameterisations). However, for consistency with the conceptual

305 framework introduced above, and because ecologists are more familiar with direct examinations

306 of diversity measures, we estimated four metrics: total numbers of individuals $(N)$, the expected

307 number of species for $n$ individuals $\left(S_{\mathrm{n}}\right)$, the numbers equivalent conversion of the Probability of

308 Interspecific Encounter ( $S_{\text {PIE }}$, which hereafter, we refer to as evenness due to its sensitivity to the

309 relative abundance of species), and total species richness $(S)$. The number of individuals, $n$, used

310 in the calculation of rarefied richness $\left(S_{\mathrm{n}}\right)$ was the minimum abundance observed for a given

311 comparison (i.e., within a time series or for a particular spatial comparison); observations where 
$312 n<5$ were discarded before analysis. We took this approach to rarefaction rather than first

313 extrapolating to two times the observed number of individuals (as advocated, e.g., by Chao et al.

314 2014) for consistency with the conceptual framework, and to simplify the interpretation of

315 relationships between changes in abundance, evenness and richness.

317 To estimate changes in the different metrics that account for the expected correlations between

318 them, we fit multivariate multilevel models. Similar to the way multilevel (also called

319 hierarchical or mixed-effects) models fit to a single (univariate) response allow varying (random)

320 intercepts and slopes to be correlated, this approach estimates changes in all components whilst

321 allowing for correlations between them.

323 Temporal comparisons: natural environmental variation

324 To quantify temporal change among natural assemblages at the local scale, we used the

325 BioTIME database (Dornelas et al. 2018), which documents over 45 thousand species in time

326 series with an average duration of 13 years. Taxonomic groups in our analysis came from

327 surveys in marine, freshwater and terrestrial ecosystems, and included plants (and other

328 producers), invertebrates, fish, amphibians, reptiles, birds, and mammals, as well as several

329 surveys that collected data from multiple taxa. Here, we only used time series that had numerical

330 abundance data available (i.e., studies that recorded counts of the number of individuals for each

331 species in an assemblage), and our analysis included 288 studies. Locations sampled in the

332 BioTIME database document places with varying degrees of anthropogenic environmental

333 change, but do not include manipulated assemblages or before-after-control-impact studies

334 (Dornelas et al. 2018). Accordingly, we contrast the environmental variation sampled by 
335 BioTIME with assemblage time series that experienced documented perturbations (see Temporal comparisons: experimental or natural perturbations).

338 To quantify changes at the local scale within BioTIME, studies with large extents were broken 339 up into smaller cell-level time series while still maintaining the integrity of individual studies

340 (i.e., different studies were not combined, even when samples were collected in the same grid 341 cell). We used sample-based rarefaction (Gotelli \& Colwell 2001) to standardise the number of

342 samples per year for each time series (see Blowes et al. 2019 for details). For the calculation of

343 rarefied richness $\left(S_{\mathrm{n}}\right)$, the minimum total number of individuals was determined for each time

344 series, and set as the target $n$ for which expected richness was calculated; cell-level time series

345 where $n<5$ were discarded. This process resulted in 42,604 cell-level time series from the 288

346 studies, and we focus on the study-level estimates of change in our results and discussion.

Temporal comparisons: experimental or natural perturbations

349 To complement the environmental variation sampled by the BioTIME database, we searched for

350 time series data with either experimental or natural perturbations from the U.S. LTER network

351 (including terrestrial, freshwater and marine systems of multiple taxa) using the Data Portal of

352 the Environmental Data Initiative (https://portal.edirepository.org/nis/home.jsp). Following data

353 standardisation (i.e., minimum of five individuals per sample, and standardisation of sample

354 effort through time), our analysis included 11 studies (see supplementary material) and temporal

355 change was estimated in 63 study-treatment combinations. Natural and experimental treatments

356 included changes due to warming, eutrophication, fire, grazing, restoration, severe storms or 
357 other disturbances, and kelp removal. Taxonomic groups included algae, plants, invertebrates,

358 fish, birds, and mammals.

360 Spatial comparisons: natural environmental variation

361 To examine spatial patterns of biodiversity change across relatively natural environmental

362 contexts (and without obvious human impacts), we combined two existing compilations of data.

363 The CESTES database (Jeliazkov et al. 2019) contains assemblage data from studies that

364 sampled species at multiple sites (it also includes information on traits and environment that we

365 do not use here), and a compilation of datasets with two or more local assemblages containing

366 species abundance data (McGill 2011b). From CESTES, we excluded studies with explicit

367 human impacts identified as an environmental feature, and our analysis included 19 studies that

368 sampled terrestrial, freshwater and marine assemblages from a number of taxonomic groups

369 (birds, plants, insects, macroinvertebrates, fishes and mammals). Similarly, studies documenting

370 disturbances and other perturbations were removed from the McGill (2011b) compilation,

371 resulting in 32 studies being retained. From the combined 51 studies, those with many sites were

372 randomly subsampled down to ten sites so that they did not dominate the results. Within each

373 study, an arbitrary site was assigned as the 'reference' site, and change was quantified between

374 every site and the reference within studies; our analysis included a total of 356 spatial

375 comparisons.

377 Spatial comparisons: anthropogenic perturbations

378 To quantify spatial differences in biodiversity due to anthropogenic land use, we used the

379 PREDICTS database, which is a collation of studies comparing reference to impacted sites 
380 (Hudson et al. 2017). Here we used the 2016 release of the database (downloaded from

381 https://data.nhm.ac.uk/ on $10^{\text {th }}$ July 2020). We limited our analyses to studies with abundance

382 data for individuals, and those with known land use categories (primary vegetation, mature

383 secondary vegetation, intermediate secondary vegetation, plantation forest, cropland, pasture,

384 and urban); studies where land use was not recorded were omitted. This resulted in 237

385 combinations of source ID and study (some sources had multiple studies, denoted SS in the

386 database), and 418 estimates of change relative to the reference land use category, primary

387 vegetation.

\section{Statistical models}

390 Similar models were fit to each data source. For the Temporal comparisons: natural

391 environmental variation data, total abundance $(N)$ was fit with a model that assumed a lognormal

392 distribution and identity link function, and Poisson distributions with log link functions were fit

393 to $S_{\mathrm{n}}, S_{\text {PIE }}$ and S; Poisson distributions were chosen for $S_{\mathrm{n}}$ and $S_{\text {PIE values rounded to integers }}$

394 based on visual assessments that showed lognormal models fit to raw $S_{\mathrm{n}}$ and $S_{\text {PIE values greatly }}$

395 underpredicted the density of ones in the data. For the Temporal comparisons: experimental or

396 natural perturbations data, $S$ was no longer an integer value after standardising sampling effort,

397 and all metrics were fit with models that assumed lognormal distributions and identity link

398 functions. Both spatial data sets were fit with models that assumed lognormal distributions and

399 identity link functions for total abundance $(N)$, rarefied richness $\left(S_{\mathrm{n}}\right)$ and evenness $\left(S_{\text {PIE }}\right)$, and a

400 Possion distribution and log-link function for species richness $(S)$. 
402 The Temporal comparisons: natural environmental variation models included non-varying

403 intercepts and slopes for year, and varying intercepts and slopes for studies and cells for all

404 responses. To allow for correlations between changes in the different responses, varying study-

405 and cell-level parameters for all responses were drawn from a single multivariate normal

406 distribution for each level (i.e., one for studies, one for cells; see supplement for equations). The

407 models fit to the Temporal comparisons: experimental or natural perturbations data similarly

408 included non-varying intercepts and slopes for year, and had varying intercepts for study, site

409 and block fitted separately for each response. For these data, correlations between changes in the

410 different responses were modelled by drawing varying intercepts and slopes for each

411 combination of treatment and study for all responses from a single multivariate normal

412 distribution (see supplement for equations).

414 The models fit to the Spatial comparisons: natural environmental variation data included non-

415 varying intercepts for data source (i.e., CESTES and McGill). Correlations between the different

416 responses were modelled by assuming varying intercepts and slopes (representing the reference

417 site and departures for all other sites from the reference, respectively) for each study and

418 response came from a single multivariate normal distribution; over-dispersion in the richness

419 response was modelled using an observation-level varying intercept (see supplement for

420 equations). Models fit to the Spatial comparisons: anthropogenic perturbations data included

421 non-varying intercepts and slopes (representing the reference [primary vegetation] category and

422 departures from the reference for each land use category, respectively), and varying intercepts

423 for sites and blocks were modelled separately for each response. Correlations between changes in

424 the different responses were modelled by assuming that varying intercepts and slopes (as per the 
425 non-varying intercepts and slopes) for each combination of source and study and each response

426 came from a single multivariate normal distribution (see supplement for equations).

428 All statistical models were fit using the Hamiltonian Monte Carlo (HMC) sampler Stan

429 (Carpenter et al. 2017), and coded using the 'brms' package (Burkner 2017). Details of all model

430 specifications, and the iterations and warmup periods are provided in the supplement, as are the

431 priors (which were weakly regularising). Visual inspection of the HMC chains and model

432 diagnostics (Rhat $<1.05)$ showed good mixing of chains and convergence, and model adequacy

433 assessed visually using posterior predictive checks showed that the models were able to make

434 predictions similar to the empirical data (see Supplement Figures S1-4). Code for all analyses is

435 available at https://github.com/sablowes/MulticomponentBioChange, and will be archived

436 following publication.

\section{$438 \quad$ Results}

439 Temporal changes in perturbed environments had the highest percentage of assemblages with at

440 least one component trend $\left(\Delta N, \Delta S_{\mathrm{n}}, \Delta S_{\mathrm{PIE}}\right.$, or $\left.\Delta S\right)$ that differed from zero (44\%), followed by

441 spatial comparisons across land use categories (29\%), temporal changes (21\%) and spatial

442 comparisons in naturally varying environments (12\%). Component changes that differed from

443 zero showed broadly similar patterns across datasets, with one exception: trends differing from

444 zero for multiple components were less common for spatial comparisons between assemblages in 445 naturally varying environments (Figure 3). 
447 Temporal changes were typically smaller in magnitude (Figure 4a-f) and exhibited generally

448 stronger relationships across assemblages (Figure 5a, b) compared to spatial changes (Figure 4g-

449 1, Figure $5 \mathrm{c}, \mathrm{d})$. Within assemblages, changes of abundance and richness $(\Delta N, \Delta S$, Figure $4 \mathrm{a}, \mathrm{d}$,

$450 \mathrm{~g}, \mathrm{j})$, changes in rarefied richness and species richness $\left(\Delta S_{\mathrm{n}}\right.$ and $\Delta S$, Figure $\left.4 \mathrm{~b}, \mathrm{e}, \mathrm{h}, \mathrm{k}\right)$ and

451 evenness and richness changes ( $\Delta S_{\mathrm{PIE}}$ and $\Delta S$, Figure $\left.4 \mathrm{c}, \mathrm{f}, \mathrm{i}, \mathrm{l}\right)$ typically had the same sign,

452 though there were exceptions to this general pattern. For assemblages where $\Delta N$ and $\Delta S_{\text {PIE }}$ had

453 the same sign (though not necessarily differing from zero), the magnitude of richness changes

454 was typically larger (Figure 4). In contrast, if $\Delta N$ and $\Delta S_{\text {PIE }}$ had opposing signs, richness changes

455 were often of a smaller magnitude (Figure 4). This tendency for countervailing changes in

456 abundance and evenness to reduce the magnitude of richness changes was most apparent for

457 spatial changes associated with different land use categories (Figure 4j-1), and among these

458 assemblages having opposing abundance and evenness changes, there was a high proportion that

459 were growing in size $(\Delta N>0)$ but with declining species richness $(\Delta S<0$; Figure $4 \mathrm{j})$.

461 Temporal changes in naturally varying assemblages were roughly centred on zero for all metrics

462 (Figure 4a-c). Across assemblages, altered numbers of individuals and species richness changes

463 had a moderately positive relationship (Figure 5a), weakened by assemblages that had opposing

464 abundance and evenness relationships (Figure 4a). In contrast, relationships between changes in

465 species richness and rarefied richness, and between richness changes and evenness changes were

466 strong (Figure 5a). Assemblages in perturbed environments had slightly positive temporal trends

467 on average in all components (Figure 4d-f). Across assemblages, $\Delta S$ and $\Delta N$ (Figure $4 \mathrm{~d}, 5 \mathrm{~b}$ ) and

$468 \Delta S$ and $\Delta S_{\text {PIE }}\left(\right.$ Figure $4 \mathrm{f}, 5 \mathrm{~b}$ ) had relatively weak positive relationships, whereas $\Delta S$ and $\Delta S_{\mathrm{n}}$

469 (Figure 4e, 5b) showed a strong positive relationship. 
471 Spatial comparisons in naturally varying environments exhibited highly heterogeneous patterns

472 of change centred around zero for all metrics (Figure 4g-i), and decoupled component changes

473 meant that relationships between them were generally absent or weak across assemblages (Figure

474 5c). Spatial comparisons between assemblages in primary vegetation versus those in different

475 land use categories were also highly heterogeneous, though there were typically fewer

476 individuals, less even assemblages and fewer species relative to primary vegetation (Figure $4 \mathrm{j}-1)$.

477 Across assemblages, land use change was typically associated with relatively weak positive

478 relationships between changes in the components of local diversity (Figure 5d).

480 Discussion

481 Our conceptual framework showed how the expectation for positive relationships between

482 changes in abundance, evenness and richness arises, and that the signs of changes in abundance

483 and evenness hold the key to this expectation breaking down. Our empirical analyses generally

484 found support for positive relationships between abundance, richness and evenness, and within

485 assemblages, changes in multiple components were common. However, component changes

486 were also frequently highly heterogeneous within assemblages, and countervailing changes in

487 total abundance and evenness often constrained the magnitude of changes in species richness.

489 Relationships between changes in abundance, evenness, and richness were most heterogeneous

490 for spatial comparisons, and sufficiently decoupled that no strong relationships emerged across

491 assemblages. In contrast to the frequent decoupling of component changes for spatial

492 comparisons, strong positive correlations between temporal changes in species richness $(\Delta S)$ and

493 changes in metrics associated with altered SADs $\left(\Delta S_{\mathrm{n}}, \Delta S_{\mathrm{PIE}}\right)$ emerged across assemblages. This 
494 strong relationship between changes in species richness and altered SADs runs counter to the

495 common expectation that changes in the numbers of individuals underpin diversity gradients

496 (e.g., Gaston 2000, Scheiner \& Willig 2005), and shows that variation in relative abundances can

497 dominate local variation in biodiversity.

499 Variation in assemblage size does not dominate local diversity change

500 Overall, only $\sim 2 \%$ of assemblages in this study (22 of 1125) had changes consistent with a

501 strong 'more-individuals' effect on changes in species richness (i.e., $\Delta N \& \Delta S$ having the same

502 sign, and being the only changes different from zero). Despite many tests, empirical evidence for

503 the more-individuals hypothesis (Srivastava \& Lawton 1998) remains equivocal (Storch et al

504 2018, Vagle \& McCain 2020). While both (species-level) population variability and variation

505 associated with sampling (Vagle \& McCain 2020) likely contribute to the weak response of

506 species richness to variation in the total number of individuals, our results are broadly consistent

507 with previous syntheses showing that broad-scale spatial variation in richness was rarely driven

508 simply by variation in the numbers of individuals (Currie et al. 2004, Storch et al 2018). Our

509 results indicate that local assemblages changing in size are not simply passively sampling more

510 or less from a static SAD. Instead, we show that local biodiversity change can be strongly

511 influenced by changes to species' relative abundances. Changes to species' relative abundances

512 can be occurring at multiple scales (Hillebrand et al. 2008, Blowes et al. 2020), and can reflect

513 altered local environmental conditions (e.g., altered resource or habitat diversity, eutrophication,

514 local harvest or exploitation), or changes at broader scales that alter the species pool. 
516 Our general result that changes in the total abundance of an assemblage through time or space

517 are often decoupled from changes in metrics of biodiversity such as species richness also

518 cautions against making "apples to oranges" comparisons in the context of quantifying

519 biodiversity change. For example, some estimates of change are based on either population-level

520 abundance (e.g., Living Planet Index, WWF 2020), or assemblage-level abundance (e.g., insect

521 declines, Wagner 2000, van Klink et al. 2020), whereas other change estimates are based on

522 patterns of the number or identity of species present (e.g., Dornelas et al. 2014, Newbold et al.

523 2015). Our results show that assuming abundance and richness changes are strongly correlated

524 will often be an oversimplification. Moreover, the importance of variation in relative abundances

525 for local biodiversity change means that biodiversity trends may often depend on whether altered

526 relative abundances influence the metrics used (see e.g., Antão et al. 2020b).

Patterns of temporal versus spatial biodiversity change

529 Differences between patterns of temporal versus spatial change emerged from our analyses.

530 Moreover, these differences were generally greater than those found between naturally-varying

531 and perturbed assemblages, for either the temporal or spatial comparisons. In general, the

532 magnitude of changes of all components across space were larger than rates of change through

533 time. Multiple factors likely contributed to the larger effect sizes found for spatial changes. For

534 example, patterns of autocorrelation likely differ between the dimensions, with temporal data

535 more likely to resample individuals than the spatial comparisons, limiting the magnitude of

536 changes possible. Likewise, the units of change differ between temporal (where change was

537 standardised to an annual rate [change per year]) and spatial comparisons (change between

538 discrete sites). It is also possible that any given site-to-site comparison encompassed a greater 
range of environmental variation. However, it is important to note that at the local scale on which we have focussed, direct comparisons between the effect sizes are difficult.

542 Pairwise relationships between changes in abundance, evenness and richness were typically

543 weaker in space compared to time. Decoupling was greatest, and pairwise relationships weakest,

544 for spatial comparisons between sites with relatively natural environmental variation. These

545 highly variable component changes to environmental variation emphasise the need for a

546 wholistic approach to quantifying community changes (Avolio et al. 2021). Our conceptual

547 framework showed that the signs of changes in abundance and evenness can strongly constrain

548 the magnitude of richness changes, a pattern generally supported by our empirical analyses. In

549 particular, we found that the signs of abundance and evenness changes often determined the

550 magnitude of richness losses associated with land use modification (Newbold et al. 2015, 2020).

551 Assemblages with the greatest declines in abundance and evenness had the greatest richness

552 declines. In contrast, when changes in abundance and evenness were in opposite directions,

553 richness changes were tempered. Indeed, countervailing abundance and evenness changes were

554 frequently associated with components other than species richness (i.e., $\Delta N, \Delta S_{\mathrm{n}}$, and/or $\Delta S_{\mathrm{PIE}}$ )

555 having a trend that differed from zero across all data sources (Supplementary Table 1). This

556 shows that even for apparently decoupled component changes, interdependencies between

557 biodiversity components remain important to overall biodiversity change.

559 In contrast to assemblage changes between sites, there was strong coupling between species

560 richness and SAD changes through time. In particular, the strength of the relationship between

$561 \Delta S_{\mathrm{n}}$ and $\Delta S$ resulted in estimates of change being similar for most assemblage time series in 
562 relatively natural environments (Figure $4 \mathrm{~b}$ ). In some cases, this occurred despite countervailing

563 changes in total abundance and evenness (Figure 4a, b). For assemblages where abundance and

564 evenness changed in the same direction, similar estimates of $\Delta S_{\mathrm{n}}$ and $\Delta S$ indicate that abundance

565 changes were occurring along a relatively flat region of the individual-based rarefaction curve.

566 This shows that changes to the total number of individuals need not strongly influence species

567 richness, even where signs are the same and they have a positive relationship. Instead, richness

568 changes were more strongly associated with altered relative abundances, which has important

569 implications for examining causes and/or consequences of biodiversity change (Hillebrand et al.

570 2008, Crowder et al. 2010). These cases highlight that even where the expected positive

571 relationships between abundance, evenness and richness are found, we can more fully understand

572 assemblage changes when all component changes are examined simultaneously.

574 While both approaches, time series and spatial comparisons (or space-for-time substitutions),

575 have contributed to our understanding of biodiversity change, the relative merits of each for our

576 understanding of ecological dynamics has not been discussed much (Adler et al. 2020). The

577 largely decoupled component changes found here for spatial comparisons suggest that too much

578 focus on average changes across assemblages, such as those in total abundance or in species

579 richness, risks masking highly heterogeneous changes occurring within assemblages in multiple

580 components. Moreover, decoupled, heterogeneous component changes complicate using spatial

581 comparisons to infer temporal changes. Our finding of smaller effect sizes for time series

582 indicates greater inertia for assemblage changes occurring through time, compared to site-to-site

583 variation. More generally, the strong role of changes to the SAD for variation in local

584 biodiversity suggests that examining drivers of altered patterns of relative abundance across 
585 scales (e.g., are local environmental changes affecting evenness or are changes occurring at

586 broader spatial scales impacting the size of species pool) are an important direction for future

587 empirical work.

589 Conclusions

590 We found strong correlations between changes in the SAD and species richness changes through

591 time, whereas relationships between abundance and richness changes for both temporal and

592 spatial diversity change were generally weak. Our findings confirm that altered species relative

593 abundances, and/or changes to the size of the species pool, often strongly influence local

594 diversity change (Chapin et al. 2010), even where human impacts are less direct. However, our

595 results also reinforce cautions against examining changes to any one component of biodiversity

596 change in isolation (e.g., Wilsey et al. 2005, Chase et al. 2018, Avolio et al. 2021).

598 To be most useful, variation in the different components of biodiversity need to be coherently

599 conceptualised. Individual-based rarefaction curves and associated metrics provide an intuitive

600 and illustrative characterisation of relationships among changing components of local

601 biodiversity. Whilst ecologists are increasingly looking beyond species richness to quantify

602 biodiversity change (e.g., Dornelas et al. 2014, Hillebrand et al. 2018), different components of

603 biodiversity and its change within assemblages are most often analysed independently, and with

604 metrics lacking conceptual unification. Our results emphasise that changes to the most frequently

605 quantified aspects of biodiversity, including changes to the numbers of individuals, and the

606 relative abundance and total numbers of species are highly interdependent. Examining how

607 within-assemblage component changes covary with potential drivers could reveal insights 
masked by independent aggregate estimates of change and provide new information for

understanding biodiversity change in the Anthropocene.

611 Open research statement: All data used in the manuscript are already in the public domain. The

612 BioTIME database is accessible through the BioTIME website (http://biotime.st-andrews.ac.uk)

613 and a Zenodo repository (https://zenodo.org/record/1095627). Perturbed time series were

614 compiled using the data portal of the Environmental Data Initiative

615 (https://portal.edirepository.org/nis/home.jsp); code for compilation and standardisation available

616 at https://github.com/chase-lab/BioTIMEx. PREDICTS is available at

617 https://www.predicts.org.uk/. McGill SAD data were previously archived at:

618 https://doi.org/10.6084/m9.figshare.6945704. CESTES database is available at

619 https://doi.org/10.25829/idiv.286-21-2695. Code for all analyses is available at

620 https://github.com/sablowes/MulticomponentBioChange, which will be archived when accepted.

\section{References}

623 Antão, L.H., Bates, A.E., Blowes, S.A., Waldock, C., Supp, S.R., Magurran, A.E., Dornelas, M.,

624 Schipper, A.M., 2020a. Temperature-related biodiversity change across temperate marine and

625 terrestrial systems. Nature Ecology \& Evolution 4, 927-933.

626 Antão, L.H., Pöyry, J., Leinonen, R., Roslin, T., 2020b. Contrasting latitudinal patterns in

627 diversity and stability in a high-latitude species-rich moth community. Global Ecology and

628 Biogeography 29, 896-907.

629 Avolio, M.L., Komatsu, K.J., Collins, S.L., Grman, E., Koerner, S.E., Tredennick, A.T., Wilcox,

630 K.R., Baer, S., Boughton, E.H., Britton, A.J., 2021. Determinants of community

631 compositional change are equally affected by global change. Ecology Letters 24, 1892-1904.

632 Blowes, S.A., Chase, J.M., Di Franco, A., Frid, O., Gotelli, N.J., Guidetti, P., Knight, T.M., May,

633 F., McGlinn, D.J., Micheli, F., 2020. Mediterranean marine protected areas have higher

634 biodiversity via increased evenness, not abundance. Journal of Applied Ecology 57, 578-589. 
Blowes, S.A., Supp, S.R., Antão, L.H., Bates, A., Bruelheide, H., Chase, J.M., Moyes, F., Magurran, A., McGill, B., Myers-Smith, I.H., Winter, M., Bjorkman, A.D., Bowler, D.E., Byrnes, J.E., Gonzalez, A., Hines, J., Isbell, F., Jones, H.P., Navarro, L.M., Thompson, P.L., Vellend, M., Waldock, C., Dornelas, M., 2019. The geography of biodiversity change in marine and terrestrial assemblages. Science 366, 339-345.

640 Bolker, B.M., 2008. Ecological models and data in R. Princeton University Press.

641 Bürkner, P.-C., 2017. brms: An R package for Bayesian multilevel models using Stan. Journal of 642 Statistical Software 80, 1-28.

643 Carpenter, B., Gelman, A., Hoffman, M.D., Lee, D., Goodrich, B., Betancourt, M., Brubaker, M., Guo, J., Li, P., Riddell, A., 2017. Stan: A probabilistic programming language. Journal of Statistical Software 76.

Caswell, H., 1976. Community structure: a neutral model analysis. Ecological monographs 46,

648 Cayuela, L., Gotelli, N.J., Colwell, R.K., 2015. Ecological and biogeographic null hypotheses for 649 comparing rarefaction curves. Ecological Monographs 85, 437-455.

650 Chao, A., Gotelli, N.J., Hsieh, T.C., Sander, E.L., Ma, K.H., Colwell, R.K., Ellison, A.M., n.d. 651 Rarefaction and extrapolation with Hill numbers: a framework for sampling and estimation in 652 species diversity studies. Ecology 84, 45-67.

653 Chao, A., Jost, L., 2012. Coverage-based rarefaction and extrapolation: standardizing samples by 654 completeness rather than size. Ecology 93, 2533-2547.

655 Chase, J.M., Knight, T.M., 2013. Scale-dependent effect sizes of ecological drivers on 656 biodiversity: why standardised sampling is not enough. Ecol Lett 16, 17-26. 
Chase, J.M., McGill, B.J., McGlinn, D.J., May, F., Blowes, S.A., Xiao, X., Knight, T.M., Purschke, O., Gotelli, N.J., 2018. Embracing scale-dependence to achieve a deeper understanding of biodiversity and its change across communities. Ecol Lett 21, 1737-1751.

660 Chase, J.M., McGill, B.J., Thompson, P.L., Antão, L.H., Bates, A.E., Blowes, S.A., Dornelas, M., Gonzalez, A., Magurran, A.E., Supp, S.R., Winter, M., Bjorkman, A.D., Bruelheide, H., Byrnes, J.E., Sarmento Cabral, J., Elahi, R., Gomez, C., Guzman, H.M., Isbell, F., MyersSmith, I.H., Jones, H.P., Hines, J., Vellend, M., Waldock, C., O’Connor, M., 2019. Species richness change across spatial scales. Oikos 1-13.

665 Coleman, B.D., Mares, M.A., Willig, M.R., Hsieh, Y.-H. 1982. Randomness, area, and species richness. Ecology 63: 1121-1133.

667 Connor, E.F., McCoy, E.D., 1979. The statistics and biology of the species-area relationship. The American Naturalist 113, 791-833.

669 Crowder, D.W., Northfield, T.D., Strand, M.R., Snyder, W.E., 2010. Organic agriculture

670 promotes evenness and natural pest control. Nature 466, 109-112.

671 Currie, D.J., Mittelbach, G.G., Cornell, H.V., Field, R., Guégan, J.-F., Hawkins, B.A., Kaufman, D.M., Kerr, J.T., Oberdorff, T., O’Brien, E., 2004. Predictions and tests of climate-based hypotheses of broad-scale variation in taxonomic richness. Ecology letters 7, 1121-1134.

675 wide spectrum of population trends. Nature Communications 4394.

676 Daskalova, G.N., Myers-Smith, I.H., Bjorkman, A.D., Blowes, S.A., Supp, S.R., Magurran, 677 A.E., Dornelas, M., 2020b. Landscape-scale forest loss as a catalyst of population and 678 biodiversity change. Science $368,1341-1347$. 
Díaz, S., Settele, J., Brondízio, E.S., Ngo, H.T., Agard, J., Arneth, A., Balvanera, P., Brauman, K.A., Butchart, S.H., Chan, K.M., 2019. Pervasive human-driven decline of life on Earth points to the need for transformative change. Science 366.

Dornelas, M., Antao, L.H., Moyes, F., Bates, A.E., Magurran, A.E., Adam, D., Akhmetzhanova, A.A., Appeltans, W., Arcos, J.M., Arnold, H., 2018. BioTIME: A database of biodiversity time series for the Anthropocene. Glob Ecol Biogeogr 27, 760-786.

Dornelas, M., Gotelli, N.J., McGill, B., Shimadzu, H., Moyes, F., Sievers, C., Magurran, A.E., 2014. Assemblage time series reveal biodiversity change but not systematic loss. Science 344, 296-299.

Dornelas, M., Gotelli, N.J., Shimadzu, H., Moyes, F., Magurran, A.E., McGill, B.J., 2019. A balance of winners and losers in the Anthropocene. Ecol Lett 22, 847-854.

Fisher, R.A., Corbet, A.S., Williams, C.B., 1943. The relation between the number of species

693 Gaston, K.J., 2000. Global patterns in biodiversity. Nature 405, 220-227.

694 Gotelli, N.J., Colwell, R.K., 2001. Quantifying biodiversity: procedures and pitfalls in the measurement and comparison of species richness. Ecol Lett 4, 379-391.

696 He, F., Legendre, P., 2002. Species diversity patterns derived from species-area models. Ecology $83,1185-1198$.

Hill, M.O., 1973. Diversity and evenness: a unifying notation and its consequences. Ecology 54, $427-432$.

Hillebrand, H., Bennett, D.M., Cadotte, M.W., 2008. Consequences of dominance: a review of evenness effects on local and regional ecosystem processes. Ecology 89, 1510-1520. 
Hillebrand, H., Blasius, B., Borer, E.T., Chase, J.M., Downing, J.A., Eriksson, B.K., Filstrup, species richness trends: Consequences for conservation and monitoring. Journal of Applied Ecology 55, 169-184.

711 potential feedbacks between biodiversity and disturbance. Ecology letters 10, 849-864.

712 Hurlbert, S.H., 1971. The nonconcept of species diversity: a critique and alternative parameters.

713 Ecology 52, 577-586.

714 Jeliazkov, A., Mijatovic, D., Chantepie, S., Andrew, N., Arlettaz, R., Barbaro, L., Barsoum, N.,

715 Bartonova, A., Belskaya, E., Bonada, N., 2020. A global database for metacommunity

716 ecology, integrating species, traits, environment and space. Scientific data 7, 1-15.

717 Jones, F.A., Magurran, A.E., 2018. Dominance structure of assemblages is regulated over a 718 period of rapid environmental change. Biology letters 14, 20180187.

719 Jones, F.A., Dornelas, M., Magurran, A.E., 2020. Recent increases in assemblage rarity are 720 linked to increasing local immigration. Royal Society open science 7, 192045.

721 Jost, L., 2006. Entropy and diversity. Oikos 113, 363-375.

722 Jost, L., 2007. Partitioning diversity into independent alpha and beta components. Ecology 88, $723 \quad 2427-2439$. 
724 Leung, B., Hargreaves, A.L., Greenberg, D.A., McGill, B., Dornelas, M., Freeman, R., 2020.

725 Clustered versus catastrophic global vertebrate declines. Nature 588, 267-271.

726 MacArthur, R.H., 1965. Patterns of species diversity. Biological reviews 40, 510-533.

727 Magurran, A.E., McGill, B.J., 2011. Biological diversity: frontiers in measurement and

728 assessment. Oxford University Press.

729 May, F., Gerstner, K., McGlinn, D.J., Xiao, X., Chase, J.M., 2018. mobsim: An R package for

730 the simulation and measurement of biodiversity across spatial scales. Methods in Ecology and

731 Evolution 9, 1401-1408.

732 McGill, B.J., 2011 la. Linking biodiversity patterns by autocorrelated random sampling. Am J Bot

$73398,481-502$.

734 McGill, B.J., 2011b. Species abundance distributions, in: Biological Diversity: Frontiers In

735 Measurement \& Assessment (Eds Magurran, A. \& McGill, B.). Oxford University Press, pp.

$736 \quad 105-122$.

737 McGill, B.J., Etienne, R.S., Gray, J.S., Alonso, D., Anderson, M.J., Benecha, H.K., Dornelas,

738 M., Enquist, B.J., Green, J.L., He, F., Hurlbert, A.H., Magurran, A.E., Marquet, P.A., Maurer,

739 B.A., Ostling, A., Soykan, C.U., Ugland, K.I., White, E.P., 2007. Species abundance

740 distributions: moving beyond single prediction theories to integration within an ecological

$741 \quad$ framework. Ecol Lett 10, 995-1015.

742 McGlinn, D.J., Xiao, X., May, F., Gotelli, N.J., Engel, T., Blowes, S.A., Knight, T.M., Purschke,

743 O., Chase, J.M., McGill, B.J., 2019. Measurement of Biodiversity (MoB): A method to

744 separate the scale-dependent effects of species abundance distribution, density, and

745 aggregation on diversity change. Methods in Ecology and Evolution 10, 258-269. 
McKinney, M.L., Lockwood, J.L., 1999. Biotic homogenization: a few winners replacing many losers in the next mass extinction. Trends in ecology \& evolution 14, 450-453.

Menge, B.A., Berlow, E.L., Blanchette, C.A., Navarrete, S.A., Yamada, S.B., 1994. The keystone species concept: variation in interaction strength in a rocky intertidal habitat.

$750 \quad$ Ecological monographs 64, 249-286.

751 Newbold, T., Hudson, L.N., Contu, S., Hill, S.L., Beck, J., Liu, Y., Meyer, C., Phillips, H.R.,

752 Scharlemann, J.P., Purvis, A., 2018. Widespread winners and narrow-ranged losers: Land use

753 homogenizes biodiversity in local assemblages worldwide. PLoS biology 16, e2006841.

754 Newbold, T., Hudson, L.N., Hill, S.L., Contu, S., Lysenko, I., Senior, R.A., Börger, L., Bennett,

755 D.J., Choimes, A., Collen, B., 2015. Global effects of land use on local terrestrial biodiversity.

$756 \quad$ Nature 520, 45-50.

757 Newbold, T., Oppenheimer, P., Etard, A., Williams, J.J., 2020. Tropical and Mediterranean

758 biodiversity is disproportionately sensitive to land-use and climate change. Nature Ecology \&

759 Evolution 4, 1630-1638.

760 Olszewski, T.D., 2004. A unified mathematical framework for the measurement of richness and 761 evenness within and among multiple communities. Oikos 104, 377-387.

762 Paine, R.T., 1974. Intertidal community structure. Oecologia 15, 93-120.

763 Palmer, M.W., Clark, D.B., Clark, D.A., 2000. Is the number of tree species in small tropical 764 forest plots nonrandom? Community Ecology 1, 95-101.

765 Preston, F.W., 1962. The canonical distribution of commonness and rarity: Part I. Ecology 43, $766 \quad 185-215$. 
767 Rosenberg, K.V., Dokter, A.M., Blancher, P.J., Sauer, J.R., Smith, A.C., Smith, P.A., Stanton,

768 J.C., Panjabi, A., Helft, L., Parr, M., 2019. Decline of the North American avifauna. Science

$769366,120-124$.

770 Rosenzweig, M.L., 1995. Species diversity in space and time. Cambridge University Press.

771 Scheiner, S.M., Willig, M.R., 2005. Developing unified theories in ecology as exemplified with

772 diversity gradients. The American Naturalist 166, 458-469.

773 Shmida, A.V.I., Wilson, M.V., 1985. Biological determinants of species diversity. Journal of

774 biogeography 1-20.

775 Soininen, J., Passy, S., Hillebrand, H., 2012. The relationship between species richness and

776 evenness: a meta-analysis of studies across aquatic ecosystems. Oecologia 169, 803-809.

777 Srivastava, D.S., Lawton, J.H., 1998. Why more productive sites have more species: an

778 experimental test of theory using tree-hole communities. The American Naturalist 152, 510

$779 \quad 529$.

780 Stirling, G., Wilsey, B., 2001. Empirical relationships between species richness, evenness, and

781 proportional diversity. The American Naturalist 158, 286-299.

782 Storch, D., Bohdalková, E., Okie, J., 2018. The more-individuals hypothesis revisited: the role of

783 community abundance in species richness regulation and the productivity-diversity

784 relationship. Ecol Lett 21, 920-937.

785 Tilman, D., 1982. Resource competition and community structure. Princeton University Press.

786 Vagle, G.L., McCain, C.M., n.d. Natural population variability may be masking the more-

787 individuals hypothesis. Ecology 101, e03035. 
788 Van Klink, R., Bowler, D.E., Gongalsky, K.B., Swengel, A.B., Gentile, A., Chase, J.M., 2020.

789 Meta-analysis reveals declines in terrestrial but increases in freshwater insect abundances.

$790 \quad$ Science $368,417-420$.

791 Vilà, M., Espinar, J.L., Hejda, M., Hulme, P.E., Jarošík, V., Maron, J.L., Pergl, J., Schaffner, U.,

792 Sun, Y., Pyšek, P., 2011. Ecological impacts of invasive alien plants: a meta-analysis of their

793 effects on species, communities and ecosystems. Ecology letters 14, 702-708.

794 Wagner, D.L., 2020. Insect declines in the Anthropocene. Annual review of entomology 65,

$795 \quad 457-480$.

796 Whittaker, R.J., Willis, K.J., Field, R., 2001. Scale and species richness: towards a general,

797 hierarchical theory of species diversity. Journal of biogeography 28, 453-470.

798 Wright, D.H., 1983. Species-energy theory: an extension of species-area theory. Oikos 496-506.

799 WWF, 2020. Living Planet Report 2020-Bending the curve of biodiversity loss. World Wildlife

$800 \quad$ Fund, Gland, Switzerland.

801 Zhang, Y., Chen, H.Y., Reich, P.B., 2012. Forest productivity increases with evenness, species

802 richness and trait variation: a global meta-analysis. Journal of ecology 100, 742-749.

803

804

805 
806 Figure 1: Individual-based rarefaction (IBR) curves for samples from two hypothetical

807 assemblages. We characterise diversity change using four components of the IBR curve: altered

808 numbers of individuals $(\Delta N)$, changes in species richness $(\Delta S)$, and two metrics that capture

809 changes to the SAD - changes in rarefied richness $\left(\Delta S_{\mathrm{n}}\right)$ and changes in the numbers equivalent

810 conversion of the Probability of Interspecific Encounter $\left(\Delta S_{\mathrm{PIE}}\right)$. Note, we show $\Delta \mathrm{PIE}$ on the

811 figure to illustrate changes of the PIE with the IBR, but use the numbers equivalent

812 transformation $\left(\Delta S_{\mathrm{PIE}}\right)$ in all analyses.

814 Figure 2: Relationships between component changes and potential pathways of local assemblage

815 diversity change. Different combinations of change in total abundance, evenness and richness

816 can be visualised using three pairwise relationships between metrics associated with the

817 individual-based rarefaction curve: (a) changes in species richness as a function of changes to the

818 number of individuals, (b) changes in species richness as a function of changes to rarefied

819 richness, and (c) changes in species richness as a function of changes in evenness. Dashed

820 diagonal line is $\mathrm{x}=\mathrm{y}$. Six simplified pathways of change illustrated with rarefaction curves:

821 starting from a reference assemblage (depicted with grey rarefaction curves), diversity change

822 due to (c) more individuals only, (b) more rare species, or (d) changes to the species abundance

823 distribution (e.g., increased species pool size or increased evenness) result in positive

824 relationships between combinations of $\Delta N, \Delta S_{\mathrm{n}}, \Delta S_{\mathrm{PIE}}$, and $\Delta S$. However, if the signs of $\Delta N$ and

$825 \Delta S_{\text {PIE }}$ differ, their relationships with $\Delta S$ weaken and species richness can (d) remain static, (e)

826 decrease or (f) increase. Assemblages and rarefaction curves were created using the mobsim

827 package (May et al. 2018). 
829 Figure 3: Summary of assemblage diversity components with a high probability of change (90\%

830 credible interval did not overlap zero) for (a) temporal changes in naturally varying

831 environments, (b) temporal changes in perturbed environments, (c) spatial changes relative to an

832 arbitrary reference, (d) spatial changes relative to primary vegetation. Assemblages with no

833 component changes different from zero are reported as insets for clarity. Metric abbreviations:

834 total number of individuals $(N)$, expected number of species for $\mathrm{n}$ individuals $\left(S_{\mathrm{n}}\right)$, numbers

835 equivalent transformation of the Probability of Interspecific Encounter $\left(S_{\mathrm{PIE}}\right)$, and total species

836 richness $(S)$. Number following each bar is the count of assemblages for that category.

838 Figure 4: Relationships between four components of local diversity change. Change in species

839 richness as a function of changes in the numbers of individuals (left column), rarefied richness

840 (middle column), and evenness (right column) for (a-c) study-level estimates of temporal

841 changes in naturally varying environments; (d-f) estimates of temporal change for combinations

842 of study and treatment in perturbed environments; (g-i) estimates of spatial changes within

843 studies from an arbitrary reference site along natural environmental gradients; and, (j-1) estimates

844 of spatial change within studies between primary vegetation and different land use categories.

845 Coloured concentration ellipses show 10\% increments $(5-95 \%)$ of the posterior distributions.

846 Dotted grey lines are $\mathrm{x}=\mathrm{y}=0$, and $\mathrm{x}=\mathrm{y}$ for visual reference. See Supplementary Figure 5 for

847 remaining pairwise relationships. NB: Scale of $x$ - and y-axes vary between panels; one estimate

848 with $\Delta \log (N)=-1.79, \Delta \log (S)=-3.77, \Delta \log \left(S_{\mathrm{n}}\right)=-3.23, \Delta \log \left(S_{\text {PIE }}\right)=-3.21$, removed from $(\mathrm{j}-1)$

849 for clarity. 
851 Figure 5: Component correlations among studies within each data source. Density plots for the

852 posterior distribution of pairwise correlations between component changes for (a) temporal

853 comparison in naturally varying environments, (b) temporal comparisons in perturbed

854 environments, (c) spatial comparisons along natural gradients, and (d) spatial comparisons

855 between different land use categories. NB: correlations estimated separately for sites and land

856 use categories relative to the references were combined here for clarity on (c) and (d). 
bioRxiv preprint doi: https://doi.org/10.1101/2021.08 29.458087: this version posted August 30, 2021. The copyright holder for this preprint (which was not certified by peer review) is the author/funder, who has granted bioRxiv a license to display the preprint in perpetuity. It is made available under aCC-BY-NC 4.0 International license.

\section{$858 \quad$ Figure 1}

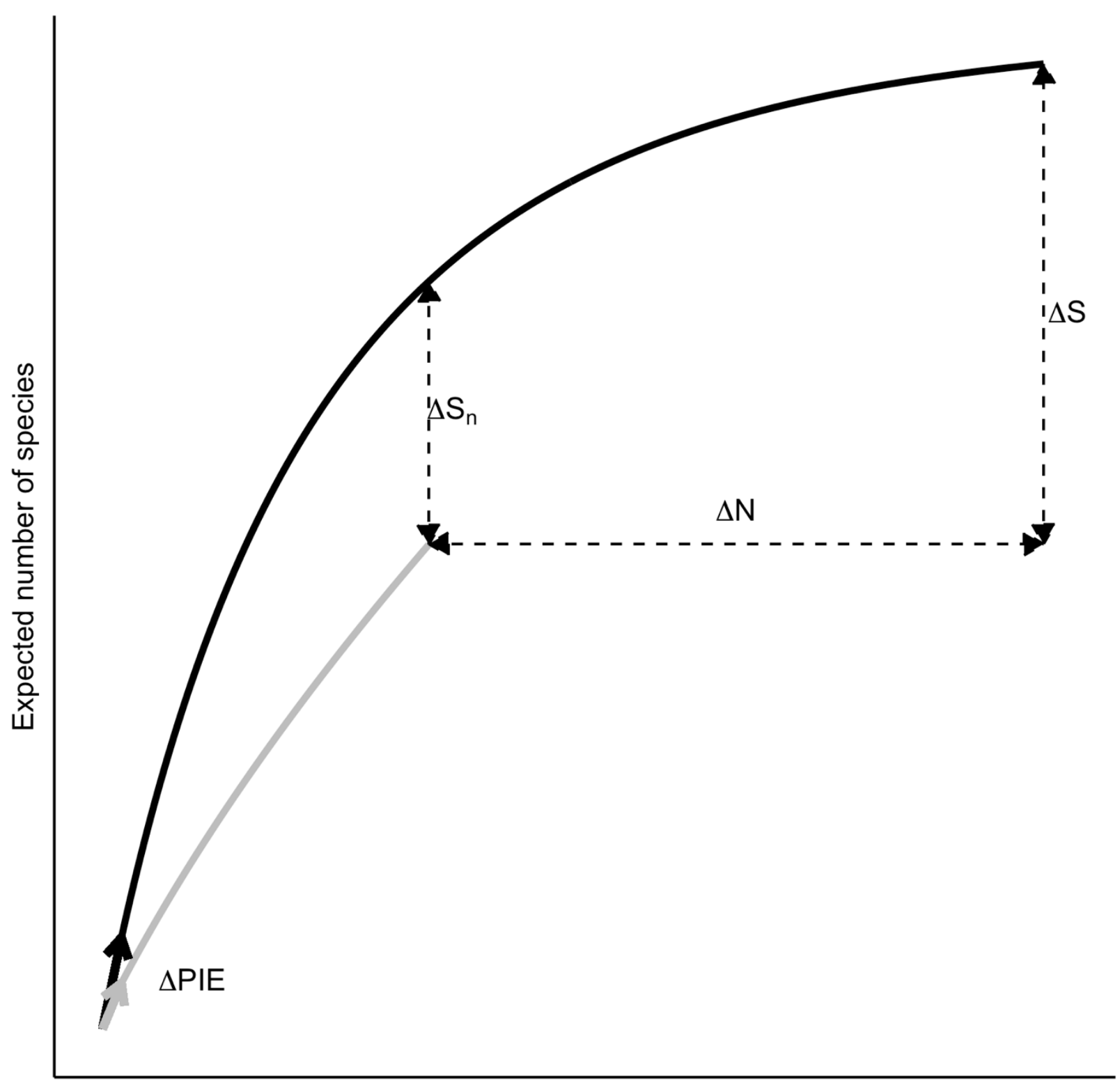


$861 \quad$ Figure 2
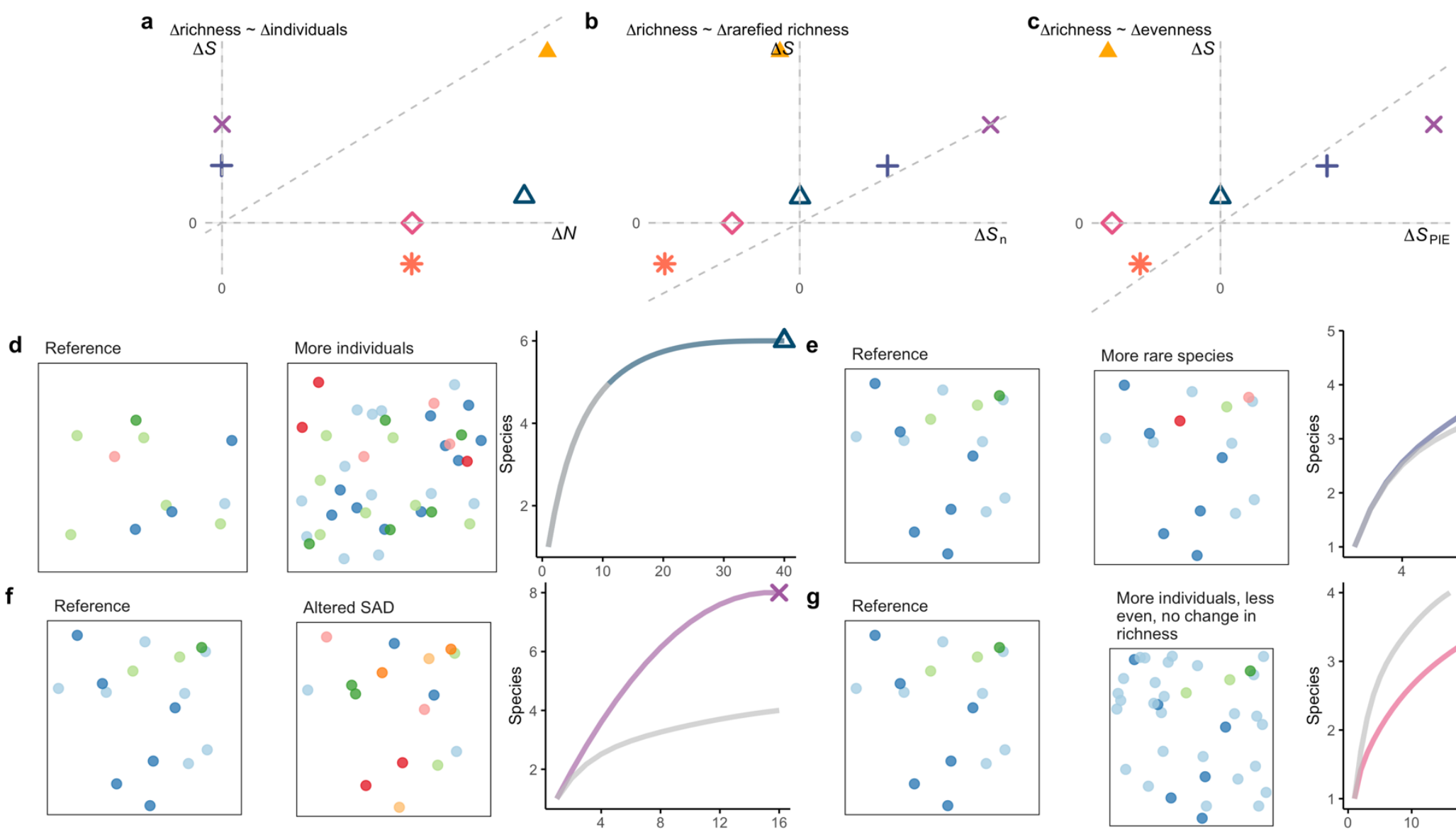

h Reference
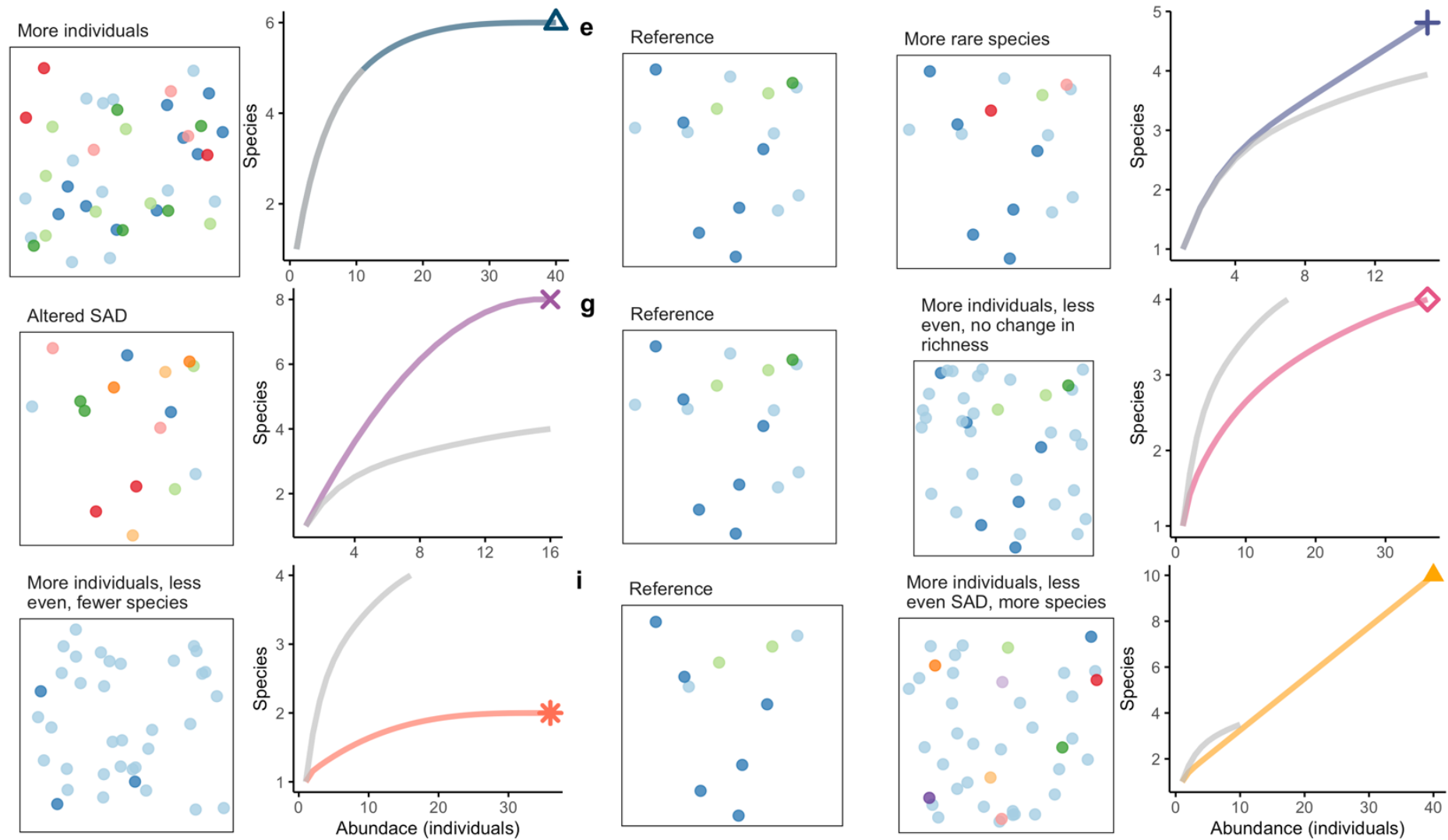

More individuals, less even, no change in richness
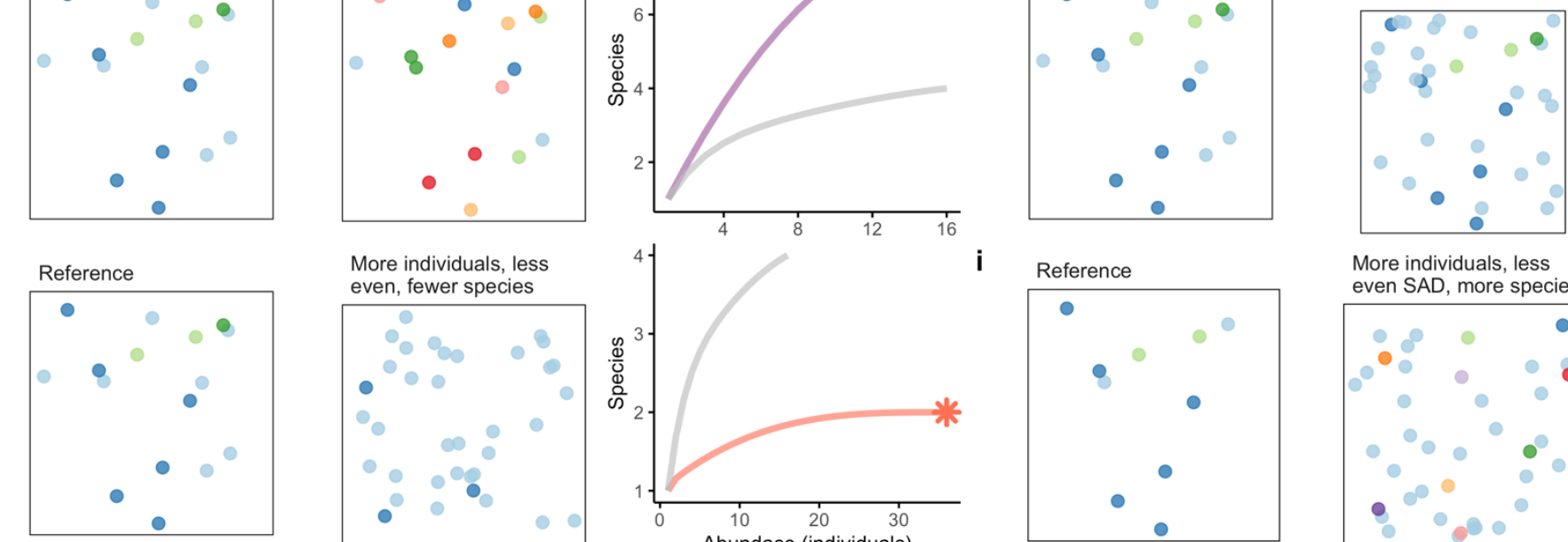

Abundace (individuals)
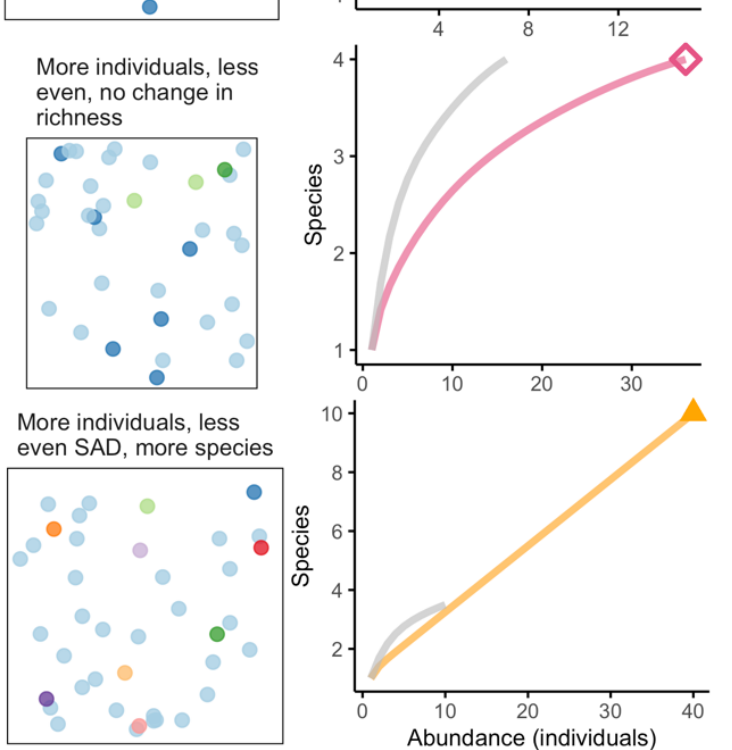
bioRxiv preprint doi: https://doi.org/10.1101/2021.08.29.458087; this version posted August 30, 2021. The copyright holder for this preprint (which was not certified by peer review) is the author/funder, who has granted bioRxiv a license to display the preprint in perpetuity. It is made available under aCC-BY-NC 4.0 International license.

\section{Figure 3}

864

a. Temporal change: natural variation

$$
\begin{array}{r}
S, S_{\mathrm{n}}, N \& S_{\mathrm{PIE}} \\
S, N \& S_{\mathrm{PIE}} \\
S_{\mathrm{n}}, N \& S_{\mathrm{PIE}} \\
N \& S_{\mathrm{PIE}} \\
S_{\mathrm{n}} \& N \\
S_{\mathrm{n}} \& S_{\mathrm{PIE}} \\
S \& N \\
S \& S_{\mathrm{PIE}} \\
S \& S_{\mathrm{n}} \\
S \\
S_{\mathrm{n}} \\
S_{\mathrm{PIE}} \\
N
\end{array}
$$

c. Spatial change: natural variation

들 $S, S_{n}, N \& S_{\mathrm{PIE}}$

$S, N \& S_{\mathrm{PIE}}$

$S_{n}, N \& S_{\mathrm{PIE}}$

$N \& S_{\mathrm{PIE}}$

$S_{\mathrm{n}} \& N$

$S_{\mathrm{n}} \& S_{\mathrm{PIE}}$

$S \& N$

$S \& S_{\mathrm{PIE}}$

$S \& S_{\mathrm{n}}$

$S$

$S_{\text {PIE }}$

N

$$
1 / 356
$$

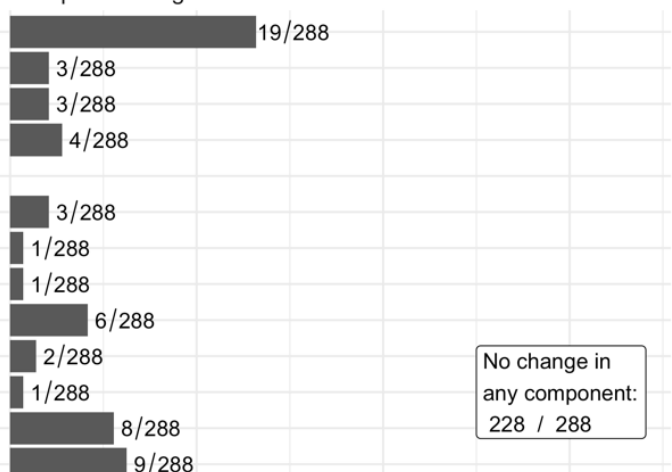

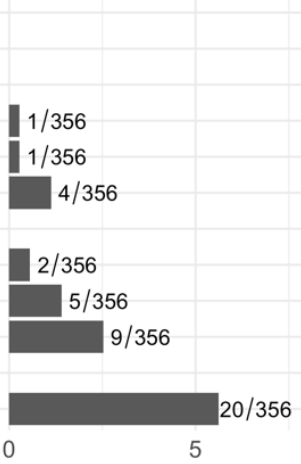

866

b. Temporal change: perturbed environments

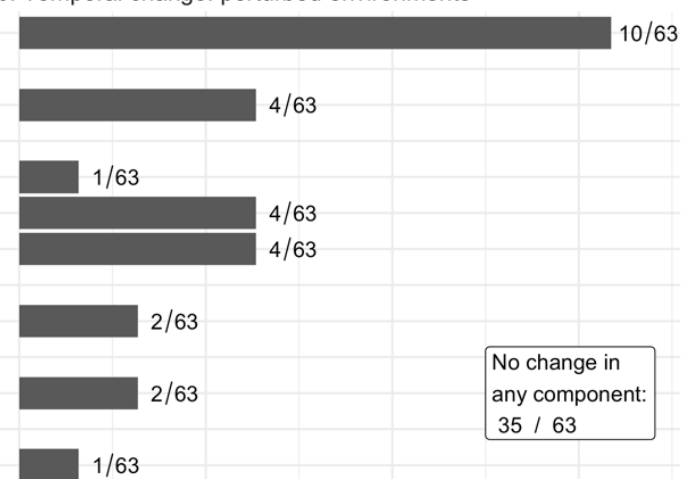

d. Spatial change: land use change

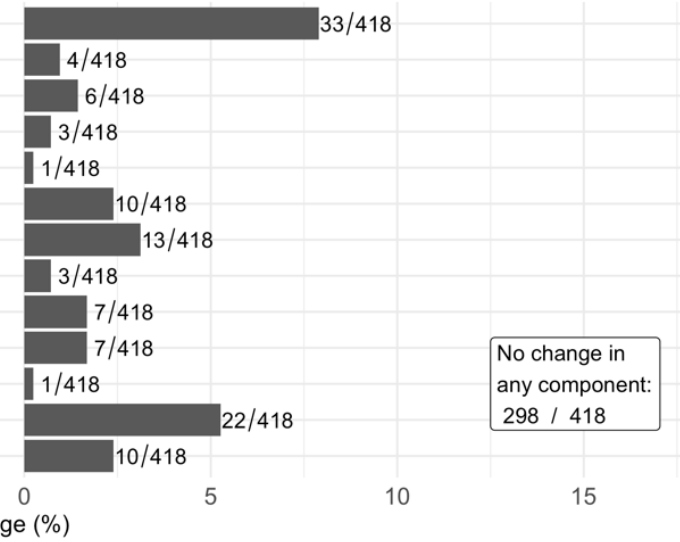


bioRxiv preprint doi: https://doi.org/10.1101/2021.08.29.458087; this version posted August 30, 2021. The copyright holder for this preprint (which was not certified by peer review) is the author/funder, who has granted bioRxiv a license to display the preprint in perpetuity. It is made available under aCC-BY-NC 4.0 International license.

Figure 4

- One or more component change differs from zero, $\Delta \mathrm{N} \& \Delta \mathrm{S}_{\mathrm{PIE}}$ have different signs

- One or more component change differs from zero, $\Delta N \& \Delta S_{\text {PIE }}$ have same signs

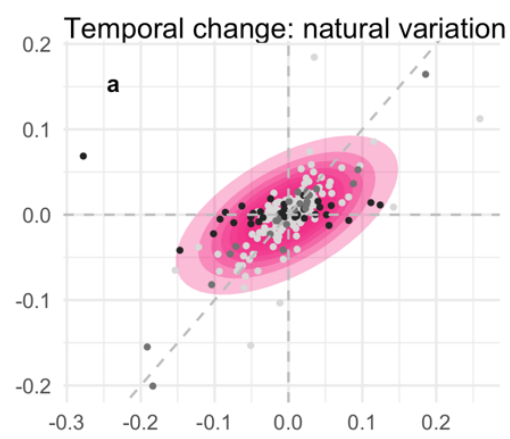

0.08 Temporal change: perturbed environments

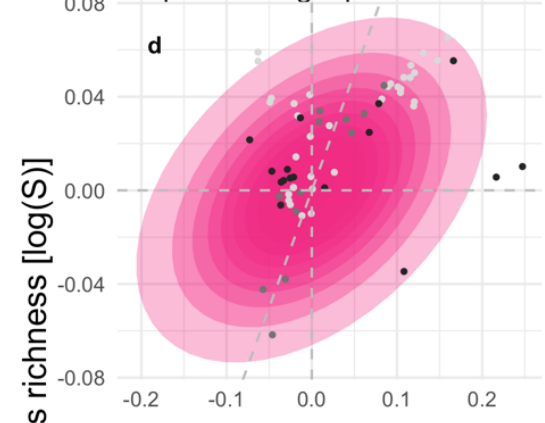

$\frac{\Phi}{0}$ Spatial change: natural variation

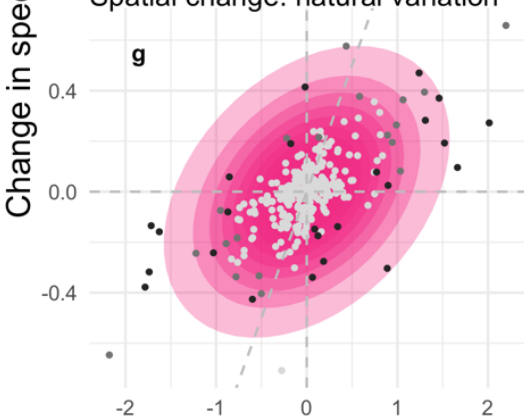

Spatial change: land use change

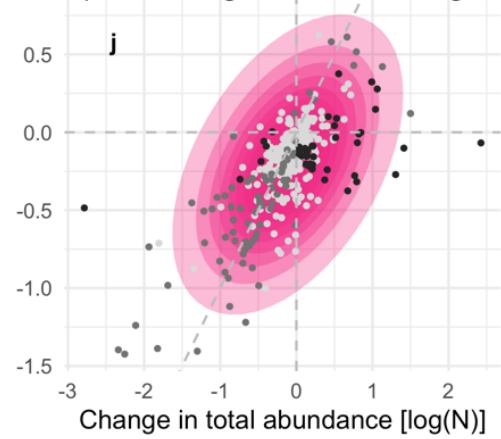

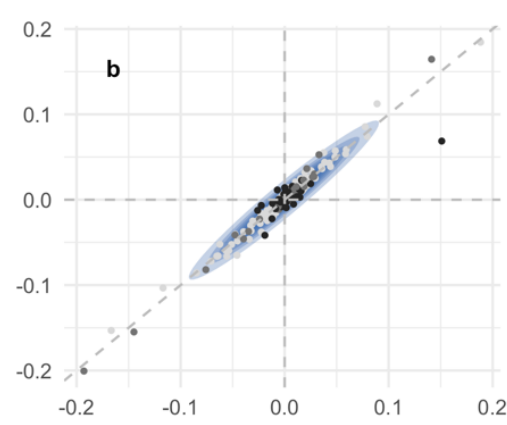

No change in any component
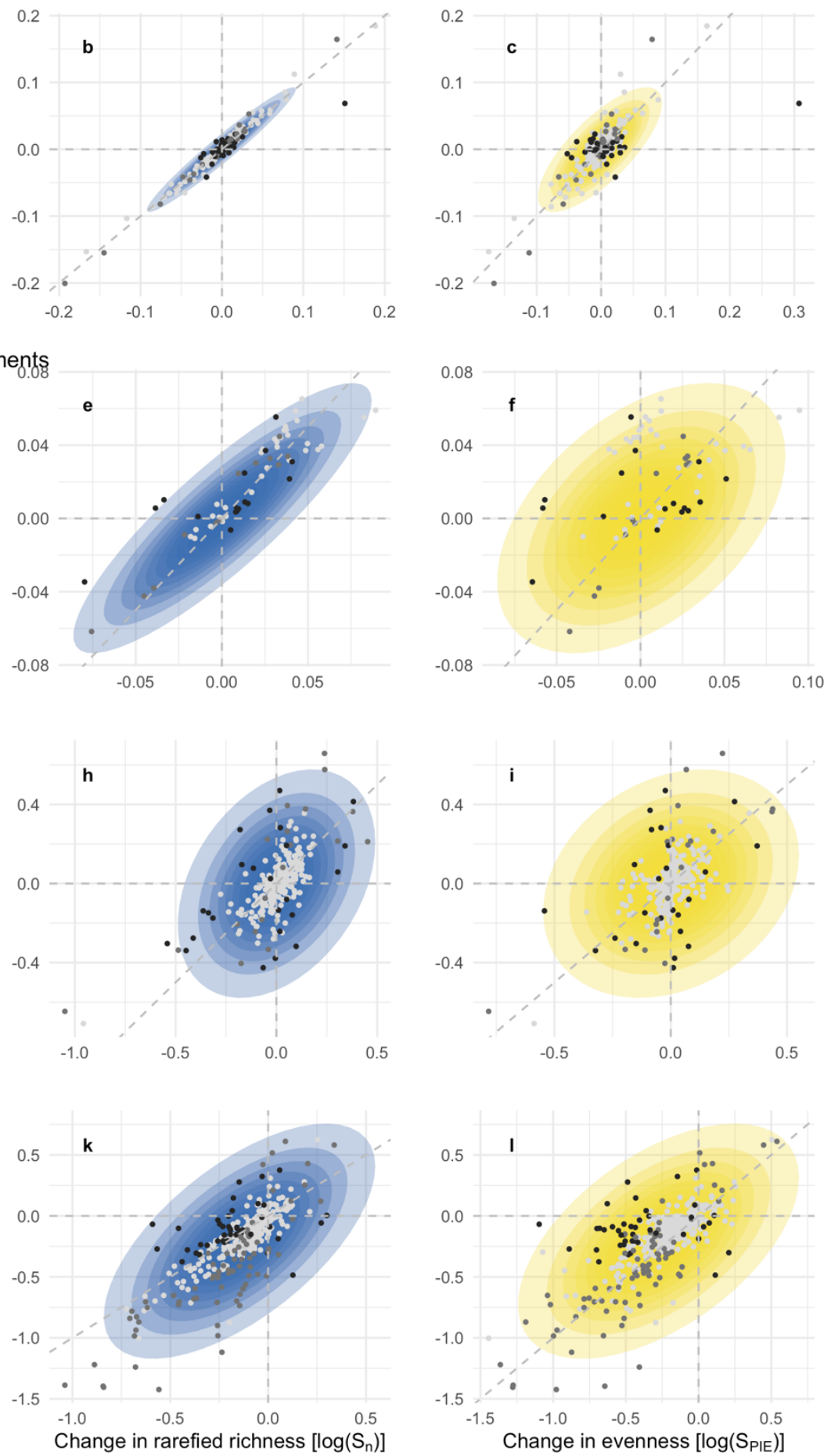


\section{Figure 5}

871

872

Temporal change: natural variation

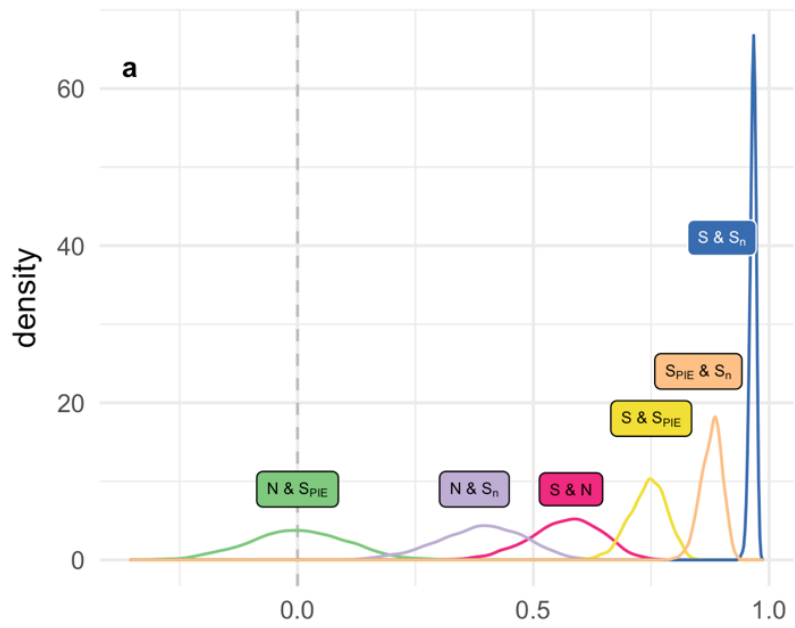

Spatial change: natural variation

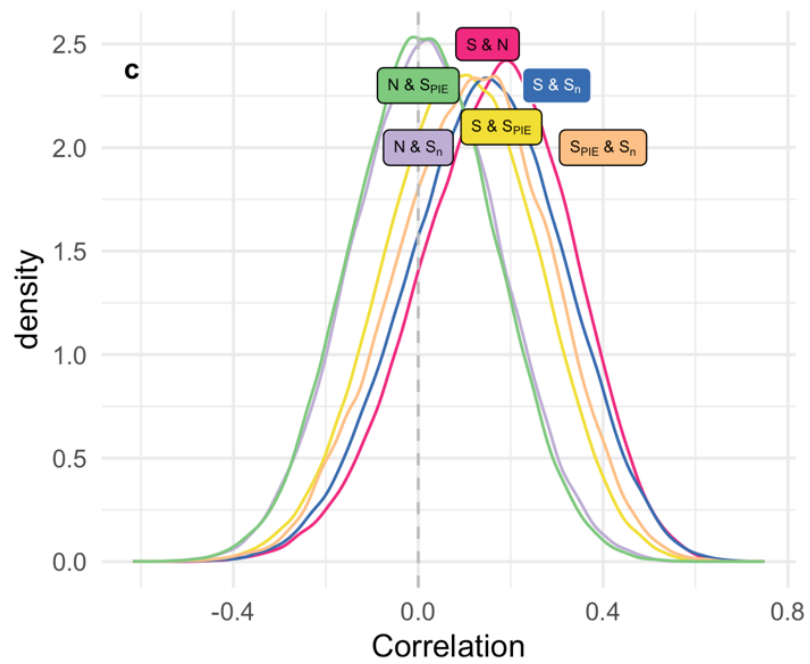

\section{Temporal change: perturbed environments}

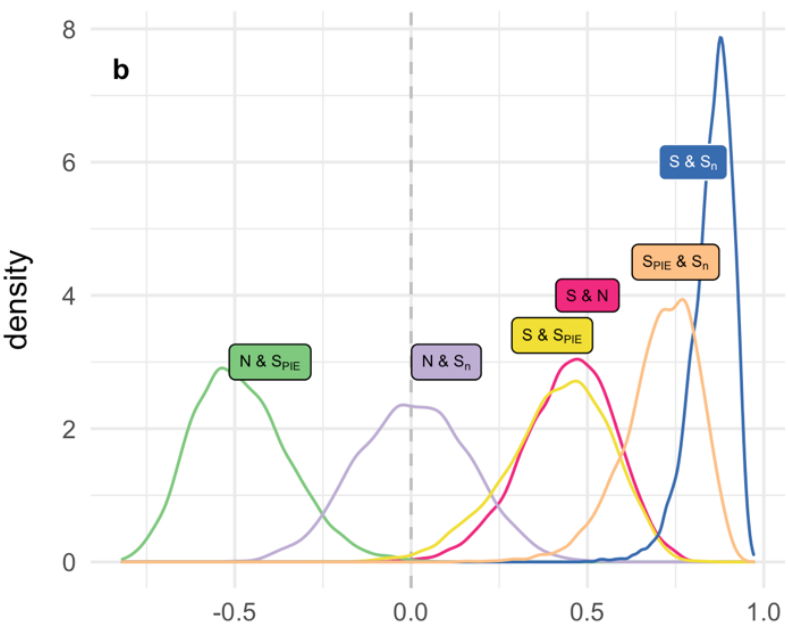

Spatial change: land use change

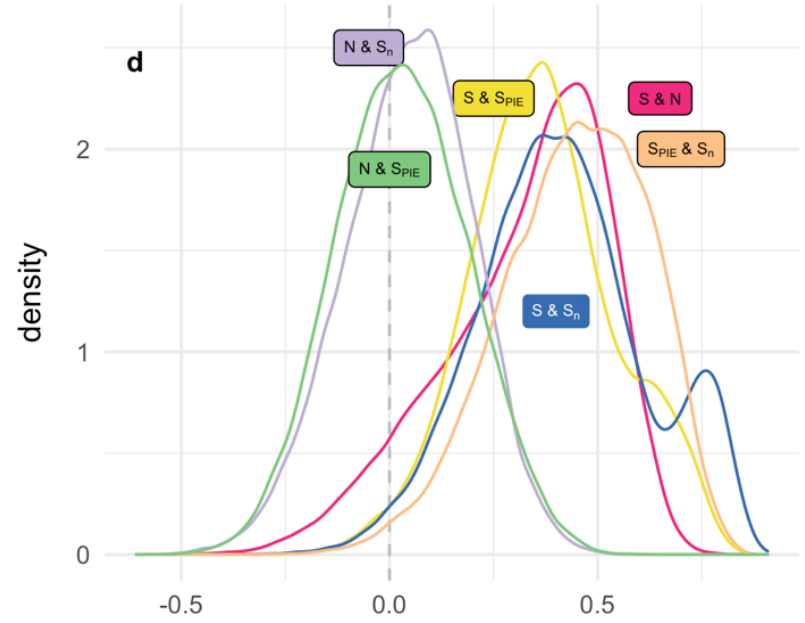

873 